\title{
New Access Openings in Genetic Science
}

\author{
Jean-François Picimbon \\ Biotechnology Research Centre, Shandong Academy of Agricultural Sciences, 202 Industry North Road, Jinan 250100, China
}

Received: June 29, 2014; Accepted: July 05, 2014; Published: July 09, 2014

${ }^{*}$ Corresponding author: Jean-François Picimbon, Functional Genomics and Proteomics of Chemical Ecology, Microbiology, Plant Transgenesis and Insect Control, Biotechnology Research Center, Shandong Academy of Agricultural Sciences, Jinan, P.R. China; Tel. +86-(531)-83175350; Fax: +86-(531)83178156; E-mail: jfpicimbon@gmail.com

SOJ Genetic Science (SOJGS) is a new online OPEN-ACCESS journal opened in the frame of Symbiosis (Bloomington, Illinois, USA) to help gather the formidable knowledge provided for studies on genome, gene, deoxyribonucleic acid (DNA), ribonucleic acid (RNA), proteins and DNA/RNA/protein complexes characterizing nowadays genetic science. Data have largely accumulated over the last few years thanks not only to the development of gene cloning, hybridization and sequencing techniques but also to the panel of biotechnological methods devoted to DNA/RNA/protein structure analysis. Modern technologies and new applications are expected to bring even further the scientific development in fast growing research fields such as gene knock out, RNA interference and organismal trans-genesis.

Geneticist biologists can feel, we are going perhaps too fast for playing with nature quickly soon after deciphering specific bacterial, plant or mammalian genomes. However, we can also somewhat feel that testing a scientific fantasy such as a genetic recombination on health, animal and human health, plant safety and/or microbe productivity is rather unavoidable for our own prosperity. RNA building blocks came from space. Now everything in the cell is DNA and RNA. What will be the future of these cells so heavily, entirely and intrinsically based on DNA and RNA? How will DNA and RNA develop in all the various cells and tissues of all various genera of living organisms? How do genomic DNA and the RNA it produces interact with each other to provide cells and tissues with proper function? How do genome and RNA evolve together to guarantee survival for all organisms? How is the whole genetic machinery controlled in vivo? What is the cell brain behind? A theory of life based on RNA mutations and protein multiplicity has been proposed (1), emphasizing the need for understanding gene-RNA-protein interaction to drive the central dogma of tomorrow research.

We open a new journal in the field of gene, genome, genetics, DNA, RNA, biology, entomology, microbiology, plant sciences, neurobiology, medicine and translational medicine for profound impact on health and health care as well as on environment and environment care, food safety and organismal engineering. Using genomics, transcriptomics and proteomics is expected to provide outstanding results and set of data to allow us to tackle most ambitious evolutionary, both fundamental and applied scientific concepts in the area of genetic sciences. Following Mendel's basic principles as well as Watson and Crick and the discovery of Deoxyribose Nucleic Acid (DNA) (2-4), genetic DNA or RNA language is not a sound wave made of four vocals (A-T-G-C or A-U-G-C) but a complex structural machinery finely orchestrated by molecular mechanisms that remain to be found, described and properly interpreted in both prokaryotes and eukaryotes.

We hope to open the gate of most original studies in this field of endeavor, genetic science, prelude to a better understanding of the functioning of all types of cells and genomes in various living organisms. We have no doubt that the cumulated literature will serve fundamental concepts from evolution to gene biotechnology and bring new issues not only in applied and basic, but also in fundamental, inherited and learned genetics life science.

"If it could be demonstrated that any complex organ existed, which could have been formed by numerous, successive, slight modifications, my theory would absolutely break down" C.R. Darwin (1859) (5).

\section{References}

1. Picimbon JF. RNA mutations: source of life. GNT. 2014; 3:2. doi:10.4172/2329-6682.1000112.

2. Mendel, JG. Versuche über Pflanzenhybriden Verhandlungen des naturforschenden Vereines in Brünn, Bd. IV für das Jahr, 1865; Abhandlungen: 3-47.

3. Windle Bertram CA. Mendel and His Theory of Heredity. A Century of Scientific Thought and Other Essays. Burns \& Oates, 1915.

4. Watson JD, Crick FH. Molecular structure of nucleic acids; a structure for deoxyribose nucleic acid. Nature. 1953; 171(4356):737-8.

5. Darwin CR On the origin of species by means of natural selection, or the preservation of favoured races in the struggle for life. Journal of Researches during H.M.S. Beagle's Voyage Round the World. London: John Murray; 1859. p. 162. 